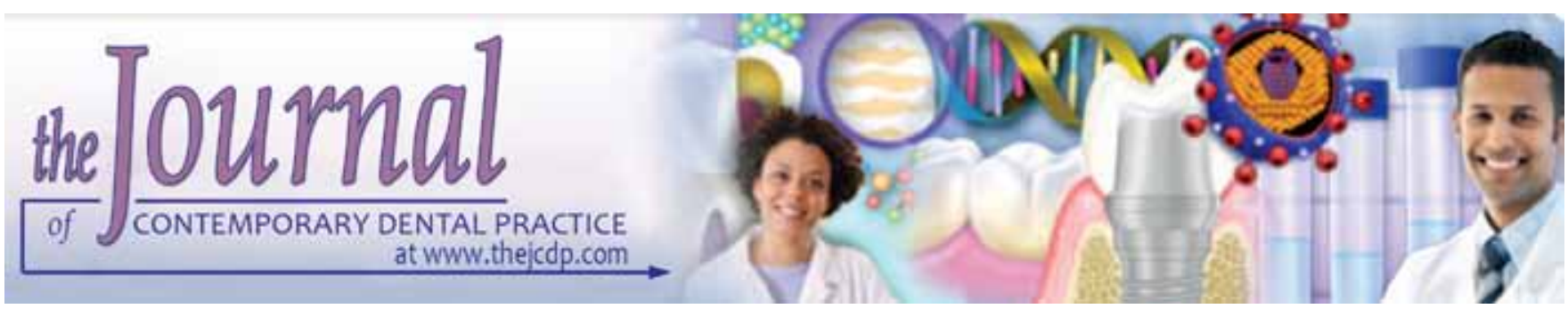

\title{
Effect of Water Storage and Additional Polymerization on the Color Parameters of Flowable Resin Composites
}

\author{
Osman Tolga Harorli, Çagatay Barutcigil, Yusuf Ziya Bayindir, Funda Bayindir
}

\section{ABSTRACT}

Aims: Tooth colored dental restorative materials should maintain their chromatic properties throughout their service period. The aim of this study was to examine the possible color changes of flowable resin composite filling materials following water storage. The effect of additional light curing on color stability of restorative materials was also investigated.

Materials and methods: Six brands of light-cured flowable resin composites of the same shade (A3) were prepared from two groups generated by curing for 20 or 60 seconds. The initial color parameters of the flowable composite samples were measured with a dental colorimeter according to the CIELAB color scale, and the samples were stored in distilled water at $37^{\circ} \mathrm{C}$. Following 2 weeks' water storage, the measurements were repeated. The color differences $\left(\Delta \mathrm{E}^{*}{ }_{\mathrm{ab}}\right)$ were calculated according to the CIELAB formula. Statistical differences between the measurements were analyzed by ANOVA and Duncan's tests.

Results: No initial color variation between the samples cured for 20 seconds and 60 seconds was perceptible $\left(\Delta E^{*}{ }_{a b}<3.3\right)$. However, after 2 weeks' water storage, a noticeable color change, $\Delta \mathrm{E}^{*}{ }_{\mathrm{ab}}>3.3$, was detected in Eco-flow, Filtek Supreme and Grandio samples in both polymerization groups.

Conclusion: Flowable resin composites may exhibit a significant color change as a result of water storage. Sixty seconds exposure period does not influence the final color.

Clinical significance: Clinicians should be aware of color shifts in flowable resins.

Keywords: Color stability, Flowable composite, Polymerization, Water storage.

How to cite this article: Harorli OT, Barutcigil C, Bayindir YZ, Bayindir F. Effect of Water Storage and Additional Polymerization on the Color Parameters of Flowable Resin Composites. J Contemp Dent Pract 2013;14(6):1109-1114.

Source of support: Nil

Conflict of interest: None declared

\section{INTRODUCTION}

Presently, flowable composites are regularly used in esthetic applications. These are the material of choice for cervical lesions, enamel defects, minor margin and void cracks. ${ }^{1}$ Compared with universal dental composites, these materials offer greater flow, improved adaptation to the cavity wall, easier insertion and greater elasticity. ${ }^{2}$ In common with other esthetic restorative materials, flowable resin composites are expected to maintain their color properties in oral environment.

Correct shade selection and proper clinical procedures may be invalidated as a result of color alteration of restorative material. Color shifting in resin-based materials may be due to intrinsic and extrinsic factors. Intrinsic color staining is an important reason for the esthetic failure of resin composites. Two major factors that affect the intrinsic color change are the composition of the composite resin and the degree of remaining $\mathrm{C}=\mathrm{C}$ bonds. Minimizing the unreacted monomer rate by extra polymerization could improve the color stability of the composite resin. Increased irradiant energy application leads to significant increases in the degree of conversion. ${ }^{3}$ Due to the proportion of the resin matrix, flowable composites are relevant candidates for testing the effect of additional curing on color stability.

Restorative materials may absorb significant amounts of water in an aqueous environment. ${ }^{4}$ Water accumulation is thought to be an important reason for internal color changes. Water acts as a discoloring agent and may lead to color instability and variations in opacity. A greater amount of resin matrix results in increased discoloration. The high organic content of the composite results in greater water sorption and discoloration over time, as already demonstrated for microfilled composites where the organic content is higher than the microhybrid content. ${ }^{5}$ Flowable 
resin composites have a large amount of resin ingredient for this reason their color stability should be questioned.

The Commission Internationale de l'Eclairage (CIE) LAB system is generally used to determine color measurements. In this $3 \mathrm{D}$ color space system, the location of a particular shade in the color space is defined by three coordinates: $\mathrm{L}^{*}, \mathrm{a}^{*}$ and $b^{*} . L^{*}$ in the CIELAB color system serves as the correlate of lightness, $\mathrm{a}^{*}$ value is a measure of redness (positive $\mathrm{a}^{*}$ ) or greenness (negative $a^{*}$ ), and the $b^{*}$ value is a measure of yellowness (positive $b^{*}$ ) or blueness (negative $b^{*}$ ). ${ }^{6}$ The measure of the color difference between two objects can be described by $\Delta \mathrm{E}^{*}{ }_{\mathrm{ab}}$. In terms of $\Delta \mathrm{E}^{*}{ }_{\mathrm{ab}}$ values, the color differences can be expressed in units, which are related to visual perception and clinical significance. ${ }^{6}$

The present study was undertaken to evaluate the color stability of six different flowable composites after water storage. The two working hypotheses were water storage influences the color stability of flowable resin composites. Additional polymerization improves the color stability of flowable composites.

\section{MATERIALS AND METHODS}

Six brands of light-cured flowable resin composites were investigated (Table 1). Among the composites, shade A3 was used to minimize the influence of the shade on color differences. The flowable composites were placed in polytetrafluoroethylene molds $(10 \mathrm{~mm}$ diameter $1.5 \mathrm{~mm}$ thick) on a polyethylene terephthalate strip, and another strip was laid on the top of the specimens.

The samples were then divided into two groups. One group was light cured for 20 seconds as per the manufacturer's instructions; the other group was light cured for 60 seconds with a light curing unit (3M ESPE Elipar FreeLight II LED, Germany) to investigate the effect of extended curing. This polymerization procedure was performed from one side in a single step. During the experiments, the output of the curing light was checked with a radiometer $\left(\sim 1000 \mathrm{~mW} / \mathrm{cm}^{2}\right)$ (Hilux UltraPlus Curing Units, Benlioglu Dental Inc, Turkey). For each brand of flowable composite, five samples were prepared. All of the specimens were removed from

\begin{tabular}{|c|c|c|c|c|}
\hline Material & Ratch & Manufacturer & Ingredients & \\
\hline \multirow[t]{2}{*}{ Admira Flow } & \multirow[t]{2}{*}{721521} & \multirow{2}{*}{$\begin{array}{l}\text { Voco, Cuxhaven } \\
\text { Germany }\end{array}$} & UDMA \% 4-6 & \\
\hline & & & $\begin{array}{l}\text { Mixture different dimethacrylates, silicate fillers, } \\
\text { ormocers, initiators and different additives }\end{array}$ & \\
\hline \multirow[t]{2}{*}{ Clearfil Majesty Flow } & \multirow[t]{2}{*}{ 00204-A } & \multirow[t]{2}{*}{$\begin{array}{l}\text { Kuraray Medical Inc., } \\
\text { Okayama, Japan }\end{array}$} & $<7 \%$ TEGDMA & \\
\hline & & & $\begin{array}{l}\text { Hydrophobic aromatic dimethacrylate, Silanated } \\
\text { barium glass filler, Silanated colloidal silica, dl- } \\
\text { Camphorquinone, Accelerators, Pigments, Other }\end{array}$ & \\
\hline \multirow[t]{4}{*}{ Te-econom Flow } & \multirow[t]{4}{*}{ K05952 } & \multirow{4}{*}{$\begin{array}{l}\text { Ivoclar, Vivadent- } \\
\text { Schaan Liechtenstein }\end{array}$} & Bis-GMA & $<15 \%$ \\
\hline & & & UDMA & $<16 \%$ \\
\hline & & & TEGDMA & $<8 \%$ \\
\hline & & & $\begin{array}{l}\text { Paste of dimethacrylates, inorganic fillers, initiators, } \\
\text { stabilizers and pigments }\end{array}$ & \\
\hline \multirow{5}{*}{$\begin{array}{l}\text { Filtek Flow Flowable } \\
\text { Restorative }\end{array}$} & \multirow[t]{5}{*}{$5 F A$} & \multirow[t]{5}{*}{ 3M ESPE,USA } & BIS-GMA & $10-20 \%$ by wt \\
\hline & & & TEGDMA & $10-20 \%$ by wt \\
\hline & & & Silane treated ceramic & $55-65 \%$ by wt \\
\hline & & & Silane treated silica & $5-10 \%$ by wt \\
\hline & & & Functionalized dimethacrylate polymer & $<5 \%$ by wt \\
\hline \multirow{7}{*}{$\begin{array}{l}\text { Filtek Supreme XT } \\
\text { Flowable Restorative }\end{array}$} & \multirow{7}{*}{ 7ET } & \multirow[t]{7}{*}{3 M ESPE, USA } & BISGMA & $10-15 \%$ \\
\hline & & & TEGDMA & $10-15 \%$ \\
\hline & & & Silane treated ceramic & $52-60 \%$ \\
\hline & & & Silane treated silica & $3-1 \%$ \\
\hline & & & Silane treated zirconium oxide & $3-11 \%$ \\
\hline & & & Bisphenol A polyethylene glycol diether dimethacrylate & $1-5 \%$ \\
\hline & & & Functionalized dimethacrylate polymer & $1-5 \%$ \\
\hline \multirow[t]{3}{*}{ Grandio Flow } & \multirow[t]{3}{*}{740066} & \multirow{3}{*}{$\begin{array}{l}\text { Voco, Cuxhaven, } \\
\text { Germany }\end{array}$} & BIS-GMA & $12-14 \%$ \\
\hline & & & UDMA & $12-14 \%$ \\
\hline & & & $\begin{array}{l}\text { Mixture of different dimethacrylates, microfillers, } \\
\text { silicates, catalysts, additives }\end{array}$ & \\
\hline
\end{tabular}




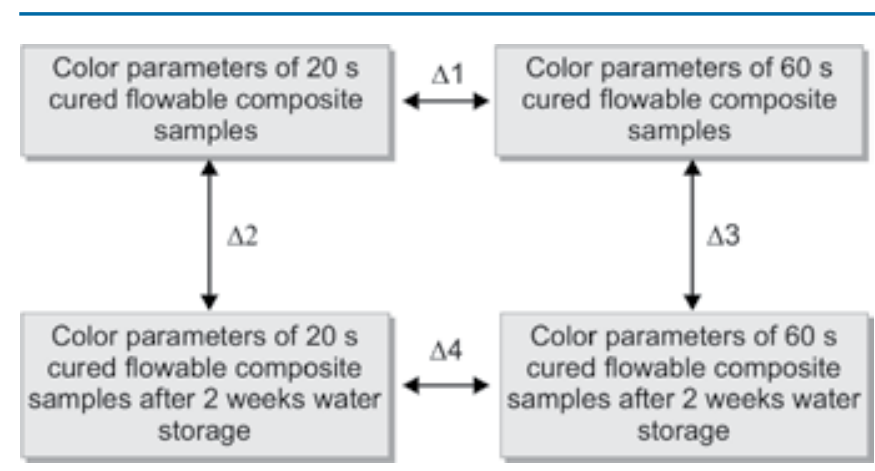

Fig. 1: Experimental set up. $\Delta 1, \Delta 2, \Delta 3$ and $\Delta 4$ represents comparisons made between color parameters

the molds. The color parameters of each sample were measured three times. The measurements were conducted with a dental colorimeter (Shade Eye NCC, Shofu, Inc., Kyoto, Japan) (tip size $3 \mathrm{~mm}$ diameter, sensor size $2 \mathrm{~mm}$ ) connected to a personal computer according to the CIE $\mathrm{L}^{*} \mathrm{a} * \mathrm{~b} *$ color scale relative to standard illumination D65 against a standard black background. Prior to measuring the properties of the composite samples, they were dried with absorbent paper, and the colorimeter was calibrated with the calibration cap supplied by the manufacturer. The tip of the dental colorimeter was placed perpendicular to the surface of the specimens. After the measurements were obtained, the samples were immersed in water for 2 weeks and stored in a dark incubator at $37^{\circ} \mathrm{C}$. The measurements were repeated again at the end of the 2 -week period. All of the color measurements were performed from the irradiated side. Experimental set up is summarized in Figure 1.

Color change $\left(\Delta \mathrm{E}^{*}\right)$ was calculated using the equation: $\Delta \mathrm{E}^{*}{ }_{\mathrm{ab}}=\left[\left(\Delta \mathrm{L}^{*}\right)^{2}+\left(\Delta \mathrm{a}^{*}\right)^{2}+\left(\Delta \mathrm{b}^{*}\right)^{2}\right]^{1 / 2}$. The chroma was

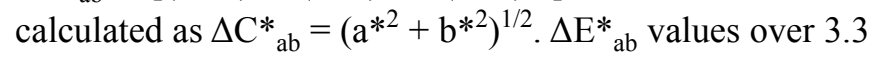
were considered to be clinically perceptible. To determine

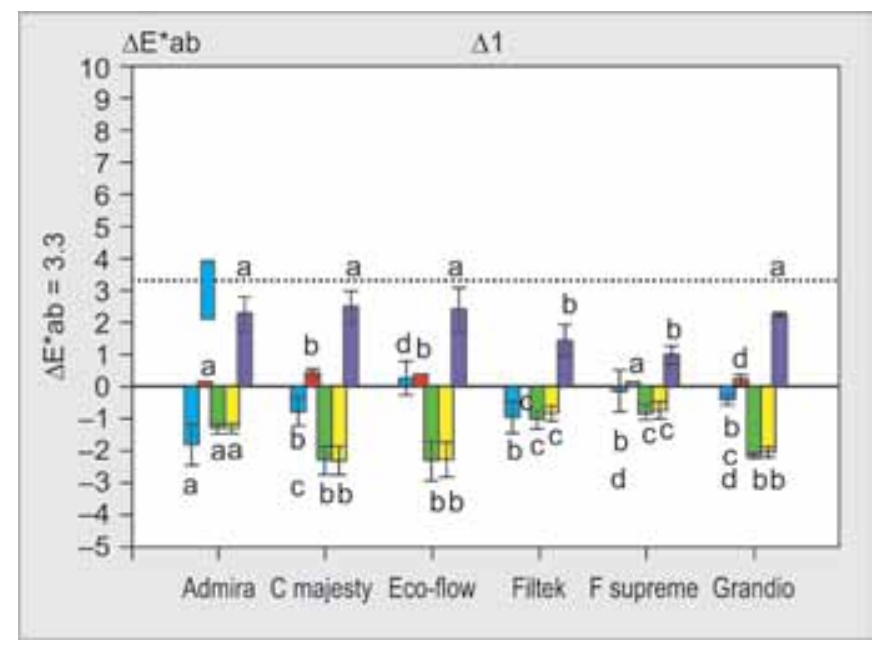

Graph 1: Color and color parameters comparison between 60 and 20 seconds cured samples $(\Delta 1)$. Error bars represent standard deviations. Letters indicate statistically significant differences of each parameter $(\alpha=0.05)$. Reference line points perceptible threshold level $\left(\Delta \mathrm{E}^{*}{ }_{\mathrm{ab}}=3.3\right)$ the influence of the brand on the polymerization changes in the color and in the color parameters, the $\Delta \mathrm{E}^{*}{ }_{\mathrm{ab}}, \Delta \mathrm{C}^{*}{ }_{\mathrm{ab}}, \Delta \mathrm{L}^{*}$, $\Delta \mathrm{a}^{*}$ and $\Delta \mathrm{b}^{*}$ values were analyzed by ANOVA and Duncan's test $(\alpha=0.05)$ (SPSS, Version 16.0; SPSS, Chicago, IL, US).

\section{RESULTS}

The mean values and the standard deviations of the color changes are presented in Table 2. Among all products, color variances between 20 and 60 second cured samples were acceptable $\left(\Delta \mathrm{E}^{*}{ }_{\mathrm{ab}}>3.3\right)$ (Graph 1). Additional polymerization caused a decrease in the $\Delta \mathrm{b}^{*}$ values of all the flowable composites. In this comparison, color changes in the Filtek Supreme samples were significantly lower than those in the other test materials $(\mathrm{p}<0.05)$.

The water storage for 2 weeks caused an unacceptable color change in the Eco-flow, Filtek Supreme, and Grandio samples cured for either 20 or 60 seconds $\left(\Delta \mathrm{E}^{*}{ }_{\mathrm{ab}}>3.3\right)$ (Graphs 2 and 3). When polymerized for 60 seconds, Clearfil Majesty samples also showed an undesirable color change following immersion in water for 2 weeks $\left(\Delta \mathrm{E}^{*}{ }_{\mathrm{ab}}>3.3\right)$ (see Graph 3).

A perceptible color change was not observed between the water-treated composite samples cured for 20 or 60 seconds $\left(\Delta \mathrm{E}_{\mathrm{ab}}^{*} \leq 3.3\right)$. Prolonging the polymerization period caused an increase in the $\Delta b^{*}$ value (Graph 4).

\section{DISCUSSION}

Tooth color can be determined with a visual assessment or with an electronic tooth color measuring device. Visual color matching is an established clinical procedure. However, several factors may complicate this process. For example, shade guides may differ by the brand of materials, they

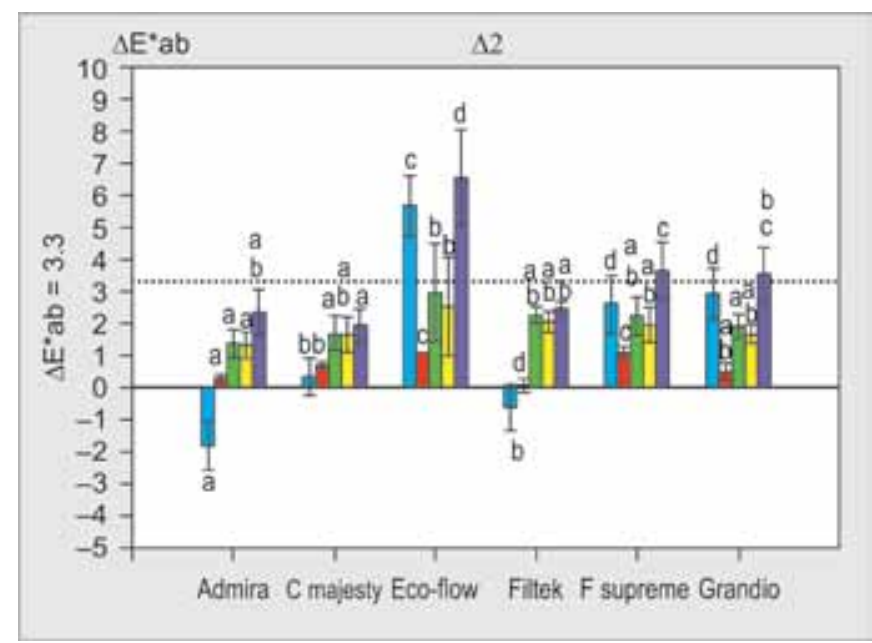

Graph 2: Mean changes in color and color parameters of 20 seconds cured samples after 2 weeks water ageing $(\Delta 2)$. Error bars represent standard deviations. Letters indicate statistically significant differences of each parameter $(\alpha=0.05)$. Reference line points perceptible threshold level $\left(\Delta \mathrm{E}^{*}{ }_{\mathrm{ab}}=3.3\right)$. 


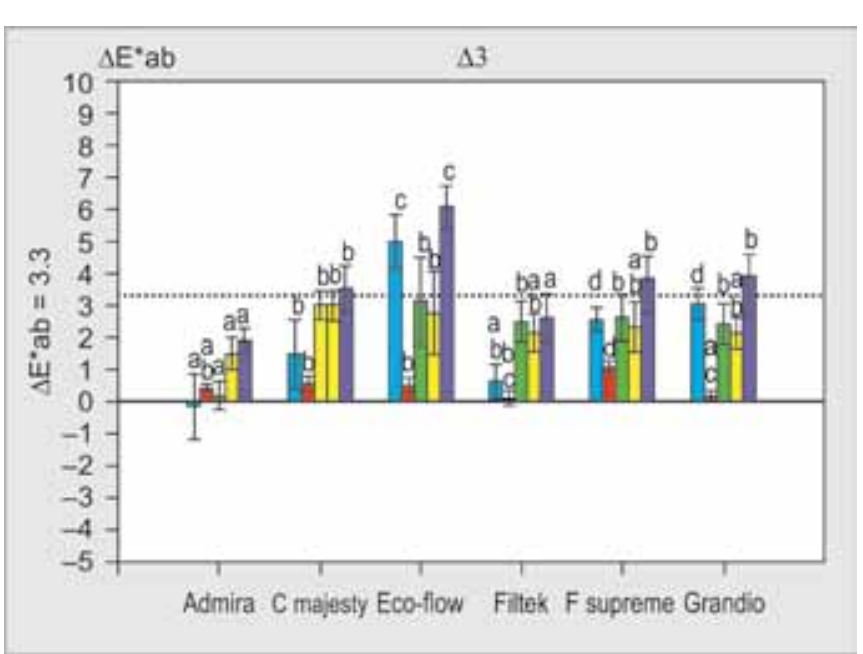

Graph 3: Mean changes in color and color parameters of $60 \mathrm{~s}$ cured samples after 2 week water ageing $(\Delta 3)$. Error bars represent standard deviations. Letters indicate statistically significant differences of each parameter $(\alpha=0.05)$. Reference line points perceptible threshold level $\left(\Delta \mathrm{E}^{*}{ }_{\mathrm{ab}}=3.3\right)$

may not provide a full range of choices relative to the tooth color observed in the population, and they may not match the colors of the resin composites. ${ }^{7}$

Although instrumental tooth shade analysis has some limitations, it is more accurate and reproducible compared with visual assessment. Colorimeters have shown good reproducibility in the measurement of composite samples because these instruments are designed to measureflatsurfaces. ${ }^{8}$

The minimum color differences detected by the human eye range from a $\Delta \mathrm{E}^{*}$ ab value of 0.3 to $0.5 .{ }^{9}$ However,

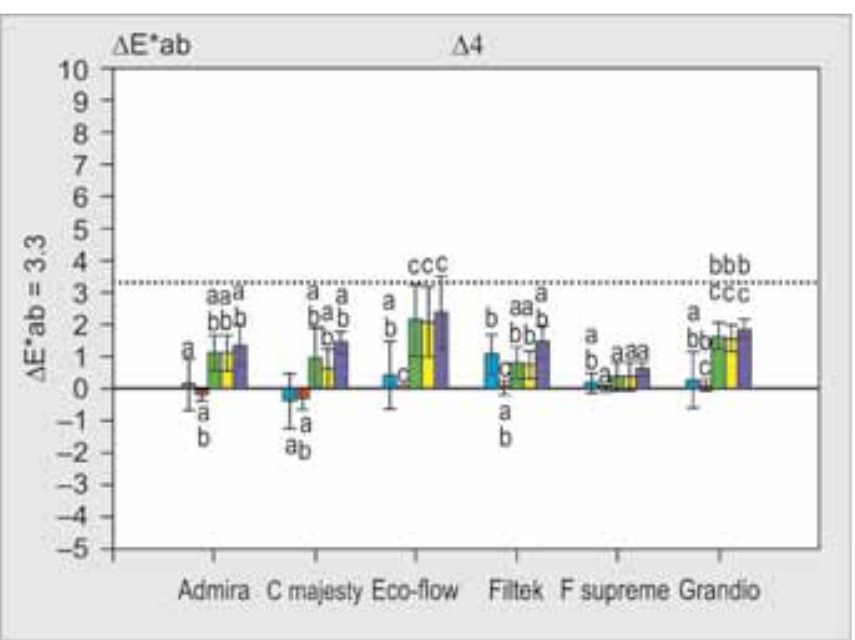

Graph 4: Color and color parameters comparison between 60 seconds cured 2 weeks water aged samples and 20 seconds cured 2 weeks water aged samples $(\Delta 4)$. Error bars represent standard deviations. Letters indicate statistically significant differences of each parameter $(\alpha=0.05)$. Reference line points perceptible threshold level $\left(\Delta \mathrm{E}^{*}{ }_{\mathrm{ab}}=3.3\right)$

acceptable thresholds are much higher and vary widely in the literature. The authors of previous studies have reported different $\Delta \mathrm{E}^{*}{ }_{\mathrm{ab}}$ values; $2.6,3.3$ and 3.7. ${ }^{9}$ In this study, the clinically acceptable threshold was 3.3 which was mentioned in a number of recent studies. ${ }^{10,11}$

Color instability of a composite resin is an important problem and a significant cause of the replacement of restorations. ${ }^{12}$ The color instability is associated with various factors such as the structure of the resin matrix, the dimensions of the filler particles, and the degree of

\begin{tabular}{|c|c|c|c|c|c|c|}
\hline Comparison & Brand & $\Delta L( \pm S D)$ & $\Delta a( \pm S D)$ & $\Delta b( \pm S D)$ & $\Delta C a b( \pm S D)$ & $\Delta E( \pm S D)$ \\
\hline \multirow[t]{6}{*}{$\Delta 1$ (60s cured-20s cured) } & Admira & $-1.81(0.64)$ & $0.10(0.02)$ & $-1.31(0.15)$ & $-1.30(0.15)$ & $2.26(0.53)$ \\
\hline & C Majesty & $-0.77(0.45)$ & $0.45(0.11)$ & $-2.29(0.44)$ & $-2.31(0.43)$ & $2.48(0.51)$ \\
\hline & Eco-Flow & $0.25(0.55)$ & $0.44(0.05)$ & $-2.30(0.63)$ & $-2.27(0.55)$ & $2.40(0.67)$ \\
\hline & Filtek & $-0.95(0.51)$ & $-0.09(0.08)$ & $-1.03(0.29)$ & $-0.83(0.23)$ & $1.43(0.49)$ \\
\hline & F Supreme & $-0.13(0.65)$ & $0.05(0.07)$ & $-0.75(0.30)$ & $-0.73(0.29)$ & $0.97(0.28)$ \\
\hline & Grandio & $-0.41(0.17)$ & $0.23(0.15)$ & $-2.15(0.08)$ & $-2.04(0.15)$ & $2.21(0.08)$ \\
\hline \multirow{6}{*}{$\begin{array}{l}\Delta 2(20 \text { s cured water } \\
\text { treated-20s cured })\end{array}$} & Admira & $-1.83(0.75)$ & $0.29(0.13)$ & $1.37(0.45)$ & $1.32(0.44)$ & $2.35(0.71)$ \\
\hline & C Majesty & $0.34(0.59)$ & $0.70(0.10)$ & $1.67(0.56)$ & $1.63(0.56)$ & $1.92(0.52)$ \\
\hline & Eco-Flow & $5.67(0.95)$ & $1.06(0.13)$ & $2.96(1.53)$ & $2.53(1.52)$ & $6.55(1.48)$ \\
\hline & Filtek & $-0.63(0.73)$ & $0.03(0.22)$ & $2.25(0.27)$ & $2.05(0.32)$ & $2.45(0.21)$ \\
\hline & F Supreme & $2.59(0.91)$ & $1.09(0.18)$ & $2.23(0.58)$ & $1.95(0.55)$ & $3.63(0.90)$ \\
\hline & Grandio & $2.91(0.80)$ & $0.49(0.28)$ & $1.89(0.38)$ & $1.66(0.29)$ & $3.51(0.87)$ \\
\hline \multirow{6}{*}{$\begin{array}{l}\Delta 3(60 \text { s cured water } \\
\text { treated-60s cured })\end{array}$} & Admira & $-0.13(1.02)$ & $0.42(0.14)$ & $0.21(0.46)$ & $1.51(0.52)$ & $1.91(0.38)$ \\
\hline & C Majesty & $1.51(1.10)$ & $0.57(0.24)$ & $3.01(0.46)$ & $3.01(0.47)$ & $3.52(0.74)$ \\
\hline & Eco-Flow & $5.00(0.85)$ & $0.53(0.23)$ & $3.14(1.36)$ & $2.75(1.29)$ & $6.07(0.67)$ \\
\hline & Filtek & $0.63(0.55)$ & $0.12(0.22)$ & $2.51(0.67)$ & $2.15(0.59)$ & $2.62(0.76)$ \\
\hline & F Supreme & $2.57(0.37)$ & $1.09(0.07)$ & $2.63(0.76)$ & $2.34(0.77)$ & $3.85(0.75)$ \\
\hline & Grandio & $3.07(0.49)$ & $0.17(0.18)$ & $2.42(0.64)$ & $2.15(0.49)$ & $3.93(0.71)$ \\
\hline \multirow{6}{*}{$\begin{array}{l}\Delta 4 \text { ( } 60 \text { s cured water } \\
\text { treated-20s cured water } \\
\text { treated) }\end{array}$} & Admira & $0.11(0.81)$ & $-0.23(0.16)$ & $1.11(0.55)$ & $1.11(0.55)$ & $1.32(0.63)$ \\
\hline & C Majesty & $-0.40(0.85)$ & $-0.31(0.36)$ & $0.94(0.93)$ & $0.61(0.61)$ & $1.42(0.36)$ \\
\hline & Eco-Flow & $0.41(1.06)$ & $0.09(0.16)$ & $2.12(1.11)$ & $2.04(1.10)$ & $2.36(1.14)$ \\
\hline & Filtek & $1.04(0.61)$ & $0.01(0.23)$ & $0.78(0.50)$ & $0.72(0.45)$ & $1.42(0.51)$ \\
\hline & F Supreme & $0.15(0.31)$ & $-0.05(0.08)$ & $0.35(0.46)$ & $0.35(0.45)$ & $0.60(0.22)$ \\
\hline & Grandio & $0.25(0.89)$ & $0.08(0.17)$ & $1.62(0.42)$ & $1.54(0.41)$ & $1.85(0.30)$ \\
\hline
\end{tabular}


conversion. ${ }^{13}$ The present study assessed the effect of water storage and additional polymerization on the color parameters of flowable resin composites.

The first hypothesis was partially supported. Water acted as a discoloring agent and caused a noticeable color change $\left(\Delta \mathrm{E}_{\mathrm{ab}}^{*}>3.3\right)$ in Eco-flow, Filtek Supreme, and Grandio samples. Water is thought to act as a vehicle for stain penetration into the resin matrix. Composite resins that can absorb water are also able to absorb other fluids containing pigments, which result in discoloration. Water sorption of the polymer is a complicated process, and the rate of water uptake is, in reality, related to the composition of the resin matrix. The water sorption of a hydrophilic resin matrix would be greater than that of a hydrophobic resin matrix. Hydrophilic groups such as the ethoxy group in triethyleneglycol dimethacrylate (TEGDMA) are thought to show affinity with water molecules by hydrogen bonding to oxygen. ${ }^{14}$ Although TEGDMA creates dense polymer networks, these are not homogeneous, and the spaces created between the polymer clusters (microporous) can accommodate a large quantity of water. ${ }^{15}$ In Bisphenol A-glycidyl methacrylate (Bis-GMA) based resins, the incorporation of greater amounts of TEGDMA results in an increase in water uptake. ${ }^{16}$

In this study, the Grandio Flow samples, which do not include TEGDMA, also showed a perceptible color change after immersion in water $\left(\Delta \mathrm{E}^{*}{ }_{\mathrm{ab}}>3.3\right)$. While the color stability of the Filtek Flow samples, which include TEGDMA (10-20\% by wt), was lower than the threshold level used in this study $\left(\Delta \mathrm{E}^{*}{ }_{\mathrm{ab}}<3.3\right)$. We reflect that, color stability is not directly related to monomer type; other components of flowable composite resins such as inorganic fillers, silanes, initiators, additives, accelerators, pigments, and stabilizers also play an important role.

The Ormocer-based flowable resin (Admira) exhibited very low $\Delta \mathrm{E}^{*}{ }_{\mathrm{ab}}$ values in both polymerization periods. The changes in the lightness values of this resin were also statistically lower than those of the tested materials $(\mathrm{p}<0.005)$.

A previous study showed that water did not differ from cola and coffee with regard to staining susceptibility. ${ }^{13}$ Water has been used as a control in various composite staining studies. However, as observed here, water storage alone can cause perceptible color changes, in this manner, water storage could affect results.

The second hypothesis was rejected. Prolonging the exposure time to 60 seconds did not improve the color stability. As reported earlier, increased monomer conversion indicates a low amount of unreacted monomer, in addition to decreased solubility and increased color stability. Lightcuring modes might interfere with the susceptibility and the retention of staining and the degree of conversion of a composite resin. Polymerization ratio may influence discoloration, as the amount of residual monomers would be reduced. ${ }^{17}$ However, no perceptible color change was detected between the composite resin samples polymerized for 60 and 20 seconds after 2 weeks' water storage. In a recent study, similar to our research, it is reported that prolonged irradiation did not improve color stability. ${ }^{18}$

The exact chemical ingredients of the test materials are not known. Sixty seconds curing caused a decrease in the CIE $b^{*}$ values, in other words the color of the flowable composites turned from yellow to blue. The change in CIE $b^{*}$ values of C. Majesty, Eco-flow, and Grandio was statistically significant $(\mathrm{p}<0.005)$. Camphorquinone is a common photo initiator used in composite resins. Only C. Majesty is known to include this photoinitiator. Although used in very small amounts, it significantly influences the material's color with its yellow chemical compound. During light irradiation at $478 \mathrm{~nm}$, camphorquinone changes its color and becomes colorless. Amine is another ingredient that can alter the final color of the composite resin, resulting in a yellowish to brownish red color. The noticed color modifications in CIE $b^{*}$ values may be due to alterations induced by a photoinitiators, such as camphorquinone.

\section{CONCLUSION}

Although the water storage period used in this study was just 2 weeks, it still caused a perceptible color change in some of the composites. Hence, clinicians should be aware of color shifts in flowable resins when using them as a direct filling material in esthetic applications. Prolonging the exposure time to 60 seconds did not improve the color stability. Further studies are necessary to better understand the esthetic properties of flowable resin composites.

\section{REFERENCES}

1. Bayne SC, Thompson JY, Swift EJ, Jr Stamatiades P Wilkerson M. A characterization of first-generation flowable composites. J Am Dent Assoc 1998 May;129(5):567-577.

2. Attar N, Tam LE, McComb D. Flow, strength, stiffness and radiopacity of flowable resin composites. J Can Dent Assoc 2003 Sep;69(8):516-521.

3. Calheiros FC, Daronch M, Rueggeberg FA, Braga RR. Influence of irradiant energy on degree of conversion, polymerization rate and shrinkage stress in an experimental resin composite system. Dent Mater 2008 Sep;24(9)1164-1168.

4. Small IC, Watson TF, Chadwick AV, Sidhu SK. Water sorption in resin-modified glass-ionomer cements: an in vitro comparison with other materials. Biomaterials 1998 Mar;19(6):545-550.

5. Loguercio AD, Zago C, Leal K, Ribeiro NR, Reis A. One-year clinical evaluation of a flowable resin liner associated with a microhybrid resin in noncarious cervical lesions. Clin Oral Investig 2005 Mar;9(1):18-20. 
6. Heydecke G, Schnitzer S, Turp JC. The color of human gingiva and mucosa: visual measurement and description of distribution. Clin Oral Investig 2005 Dec;9(4);257-265.

7. Bayindir F, Kuo S, Johnston WM, Wee AG. Coverage error of three conceptually different shade guide systems to vital unrestored dentition. J Prosthet Dent 2007 Sep;98(3)175-185.

8. Tung FF, Goldstein GR, Jang S, Hittelman E. The repeatability of an intraoral dental colorimeter. J Prosthet Dent 2002 Dec;88(6): 585-590.

9. Barutcigil C, Harorli OT, Yildiz M, Ozcan E, Arslan H, Bayindir F. The color differences of direct esthetic restorative materials after setting and compared with a shade guide. JADA 2011 Jun;142(6)658-665.

10. Kurtulmus-Yilmaz S, Cengiz E, Ulusoy N, Ozak ST, Yuksel E. The effect of home-bleaching application on the colour and translucency of five resin composites. J Dent 2013 article in press. http://dx.doi.org/10.1016/j.jdent.2012.12.007.

11. Magne P, Bruzi G, Carvalho AO, Giannini M, Maia HP. Evaluation of an anatomic dual-laminate composite resin shade guide. J Dent 2013 article in press, http://dx.doi.org/10.1016/j. jdent.2013.05.001.

12. Gordan VV, Garvan CW, Blaser PK, Mondragon E, Mjor IA. A long-term evaluation of alternative treatments to replacement of resin-based composite restorations: results of a seven-year study. J Am Dent Assoc 2009 Dec;140(12)1476-1484.

13. Aguiar FH, Georgetto MH, Soares GP, Catelan A, Dos Santos PH, Ambrosano GM, Figueroba SR, Lovadino JR. Effect of different light-curing modes on degree of conversion, staining susceptibility and stain's retention using different beverages in a nanofilled composite resin. J Esthet Restor Dent 2011 Apr;23(2):106-114.

14. Imazato $\mathrm{S}$, Tarumi $\mathrm{H}$, Kato $\mathrm{S}$, Ebisu $\mathrm{S}$. Water sorption and colour stability of composites containing the antibacterial monomer MDPB. J Dent 1999 May;27(4)279-283.
15. Sideridou I, Tserki V, Papanastasiou G. Study of water sorption, solubility and modulus of elasticity of light-cured dimethacrylatebased dental resins. Biomaterials 2003 Feb;24(4):655-665.

16. Kalachandra S, Turner DT. Water sorption of polymethacrylate networks: bis-GMA/TEGDM copolymers. J Biomed Mater Res 1987 Mar;21(3)329-338.

17. Samra AP, Pereira SK, Delgado LC, Borges CP. Color stability evaluation of aesthetic restorative materials. Braz Oral Res 2008 Jul-Sep;22(3)205-210.

18. Ruttermann S, Suyoun K, Raab WH, Janda R. Effect of exposure time on the color stability of resin-based restorative materials when polymerized with quartz-tungsten halogen and LED light. Clin Oral Investig 2010 Oct;14(5):599-605.

\section{ABOUT THE AUTHORS}

\section{Osman Tolga Harorli (Corresponding Author)}

Assistant Professor, Department of Restorative Dentistry, Akdeniz University, Turkey, e-mail: osmantolga@gmail.com

\section{Çagatay Barutcigil}

Assistant Professor, Department of Restorative Dentistry, Akdeniz University, Turkey

\section{Yusuf Ziya Bayindir}

Professor, Department of Restorative Dentistry, Atatürk University Turkey

\section{Funda Bayindir}

Professor, Department of Prosthetic Dentistry, Atatürk University Turkey 